\title{
Não-alinhamento, cooperação internacional e desenvolvimento no contexto da Guerra Fria: o caso egípcio (1955-1967) ${ }^{1}$
}

\author{
Non-alignment, foreign aid and development in the \\ Cold War context: the Egyptian case (1955-1967)
}

DOI: $10.21530 /$ ci.v13n2.2018.792

Pedro Rocha Fleury Curado²

\section{Resumo}

O objetivo deste artigo é discutir o papel funcional da política externa do não-alinhamento para as políticas de desenvolvimento econômico e militar de países periféricos durante a Guerra Fria. Para tanto, propõe-se um estudo de caso sobre a política externa do governo egípcio de Gamal Abdel Nasser (1954-1970). Ao longo do texto, argumenta-se que a política externa "não alinhada" aos principais blocos da Guerra Fria representou um poderoso instrumento de barganha internacional por parte do governo egípcio entre os anos de 1955 e de 1967. Para respaldar essa afirmação, o texto evidencia a relação existente entre, por um lado, as melhores condições externas para a viabilização dos programas internos de desenvolvimento e, por outro, as relações ambíguas cultivadas pelo governo Nasser com Estados Unidos e União Soviética. Tais relações, por sua vez, somente foram possíveis graças a um permanente jogo de compensações de ordem geopolítica que envolvia a capacidade do governo egípcio de intervir nos interesses regionais das duas superpotências.

Palavras-chave: Egito; Cooperação Internacional; Não-alinhamento; Desenvolvimento; Geopolítica.

\footnotetext{
Abstract

The objective of this article is to discuss the functional role of the non-alignment foreign policy for economical and military development of Third World countries during the Cold war. To do so, it presents a case study on the Egyptian Gamal Nasser's foreign policy (1954-1970).

1 O presente trabalho contou com financiamento da FAPERJ.

2 Professor Adjunto do Instituto de Relações Internacionais e Defesa da Universidade Federal do Rio de Janeiro (IRID-UFRJ).

Artigo submetido em 25/04/2018 e aprovado em 30/08/2018.
} 
Along the text, it argues that the "non-aligned" foreign policy in the Cold war represented a powerful instrument of international bargain by the Egyptian government. To back that statement, the text evidences the existent relationship among, on one side, the best external conditions for the foreign aid programs and, for other, the ambiguous relationships cultivated by the Nasser's government with United States and Soviet Union. Such relationships were only possible thanks to a permanent game of geopolitical compensations involving the regional interests of the two superpowers.

Keywords: Egypt; Foreign Aid; Non-alignment; Development; Geopolitics.

\section{Introdução}

O não-alinhamento foi uma estratégia de política externa difundida entre um grupo de países do então chamado Terceiro Mundo durante a Guerra Fria. Caracterizava-se pelo gerenciamento autônomo de uma agenda internacional dissociada das pressões por alinhamento automático a um dos blocos antagônicos do conflito bipolar. O presente texto objetiva discutir este modelo de posicionamento político no sistema internacional a partir de seu caráter funcional para a obtenção de acordos vantajosos no âmbito da cooperação internacional para o desenvolvimento. Como questão de fundo, busca-se responder a seguinte indagação: diante de uma conjuntura sistêmica caracterizada pela polarização entre as duas superpotências, teria a agenda “não-alinhada” representado um instrumento de efetivo suporte aos programas de desenvolvimento interno dos países não-alinhados?

Como método, adota-se a política externa egípcia sob o governo de Gamal Abdel Nasser como um estudo de caso. A partir dela, busca-se reler o processo de implementação dos programas de desenvolvimento egípcio relacionando-os à projeção geopolítica deste país durante os anos de maior intensidade da política externa não-alinhada. Mais precisamente, o marco temporal compreende os anos entre a conferência de Bandung3 (1955) e a conferência de Cartum ${ }^{4}$ (1967),

3 A Conferência de Bandung ocorreu entre os dias 18 e 24 de abril de 1955 e contou com vinte e nove países da África e da Ásia. Herdeira do movimento Afro-Asiático, a conferência buscou pressionar as potências internacionais pelo fim do colonialismo e pelo direito dos países presentes de não se vincularem a qualquer um dos blocos da Guerra Fria. A conferência de Bandung deu origem a uma série de conferências periódicas reunindo líderes de países em desenvolvimento. A partir da conferência de Belgrado, em 1961, os países participantes passaram a se declarar membros do "movimento dos não-alinhados".

4 A Conferência de Cartum foi uma conferência da Liga Árabe ocorrida em setembro de 1967. Com a derrota na Guerra dos Seis Dias (junho de 1967), o Egito, até então um importante ator no cenário regional, testemunhou a ocupação de parte de seu território (o Sinai) por Israel. Além disso, as dívidas contraídas com a participação egípcia na Guerra do Iêmen (1962-1967), somadas à perda material da Guerra dos Seis Dias, fizeram com que 
essa última realizada poucos meses após a Guerra dos Seis Dias ${ }^{5}$. Enquanto a conferência de Bandung produziu as condições materiais para o florescimento do movimento dos não-alinhados, a resolução apresentada pela conferência de Cartum, organizada pela Liga Árabe, representou o reordenamento da correlação de forças entre os Estados árabes do Oriente Médio, expondo o Egito a uma condição de fragilidade e dependência que o tornava incapaz de seguir atuando externamente com o mesmo protagonismo regional.

Representante particularmente ativo do movimento dos não-alinhados durante as décadas de 1950 e 1960, o Egito empreendeu ao longo desse mesmo período um rigoroso programa interno de industrialização acelerada e militarização do Estado, mantendo, simultaneamente, canais abertos para relações diplomáticas em alto nível com os Estados Unidos e a União Soviética. Fosse na condição de provedores de recursos financeiros, armamentos, alimentos e/ou capacitação técnica, ambas as superpotências contribuíram em alguma medida com os programas estratégicos apresentados pelo governo egípcio. Ao longo do texto, busca-se destacar a importância do não-alinhamento como fator condicionante para o papel que o Egito assumiria nas estratégias regionais de ambas as superpotências. Conforme o governo egípcio tornou-se capaz de sustentar e incrementar sua inserção no tabuleiro geopolítico do Oriente Médio, melhor posicionado esteve para celebrar programas de cooperação internacional, tanto com os Estados Unidos como com a União Soviética.

Como resultado desse processo, é importante destacar que a própria autorrepresentação de uma política externa construída em torno da recusa em aderir a um dos dois blocos da Guerra Fria legitimava-se indiretamente pela implementação interna de uma política "nacional-desenvolvimentista" de caráter híbrido, que incluísse alusões aos programas de desenvolvimento para o Terceiro Mundo propagados pela propaganda política de ambas as superpotências. Tal fenômeno era verificado tanto na referência ao modelo de industrialização acelerada soviético como na busca por uma melhor inserção na economia capitalista global e pela criação interna de uma sociedade de consumo de massa inspirada no modelo americano (CARRÉ, 1993; FARAH, 2009). Em suma, o

o governo Nasser se visse constrangido a contrair empréstimos internacionais. A ajuda financeira saudita representou, naquele momento, uma reconfiguração na correlação de forças entre aqueles dois países no contexto de uma disputa regional pela liderança dos países árabes. Sobre esse episódio, ver Oren (2002) e Halliday (2005).

5 A Guerra dos Seis Dias ocorreu em junho de 1967 e teve início com um ataque aéreo preventivo de Israel contra a Força Aérea egípcia estacionada no Sinai. Em resposta, Egito, Jordânia e Síria uniram-se para contra-atacar, mas foram derrotados. Após seis dias, Israel havia ocupado o Sinai, as Colinas de Golã e a Cisjordânia. 
não-alinhamento será aqui entendido tanto pelas relações internacionalmente construídas a partir desse posicionamento como por seus impactos domésticos. Os grandes projetos do nacional-desenvolvimentismo egípcio foram diretamente impactados pelas flutuações e instabilidades do ambiente externo, do mesmo modo que a ação internacional do governo egípcio esteve, por diversas vezes, pautada por necessidades imediatas de ordem prática relacionadas aos financiamentos, cooperação técnica, consolidação de compradores externos para commodities produzidas internamente e, em particular, provimento de armas.

O texto está dividido em quatro partes. Na primeira, destacaremos a particularidade do não-alinhamento egípcio no contexto da Guerra Fria, assim como a especificidade de seu posicionamento geopolítico para os interesses das superpotências. Na segunda, propomos analisar os acordos de cooperação estabelecidos entre o Egito e os Estados Unidos. Na terceira parte, faremos o mesmo em relação ao Egito e à União Soviética. Por fim, apresentaremos algumas considerações finais.

\section{O não-alinhamento egípcio e a Guerra Fria}

O movimento dos países não-alinhados adquiriu forma em meio à dinâmica de transposição da Guerra Fria para os novos Estados emergentes da descolonização (KENNEDY, 1989; HOBSBAWN, 1994; GADDIS, 2005). Herdeira das reivindicações políticas do movimento Afro-Asiático, a conferência de Bandung (Indonésia) de 1955 serviu como marco político para um conjunto de emergentes países reivindicarem o status "não-alinhado" diante do conflito entre os blocos da Guerra Fria. Para muitos dos países presentes, recém-saídos de variados e complexos processos de emancipação do jugo colonial, a adesão a qualquer um dos blocos era percebida como uma nova forma de subjugação nacional aos interesses externos (JANSEN, 1966). Os principais líderes que melhor expressavam o movimento dos não-alinhados nas relações internacionais eram Gamal Nasser (Egito), Jawaharlal Nerhu (Índia), Josip Broz Tito (Iugoslávia) e Sukarno (Indonésia). Posteriormente, juntar-se-iam outros líderes "terceiro-mundistas", como o argelino Ben Bella e o ganês Kwame Nkrumah. As conferências internacionais dos não-alinhados ocorreram periodicamente durante os anos de Guerra Fria e reuniram formalmente representantes de grande parte dos novos países criados ao longo do processo de descolonização da Ásia e da África. 
O surgimento do não-alinhamento como um posicionamento internacional, respaldado por um movimento composto majoritariamente por novos Estados independentes, impactou nas relações construídas entre Estados Unidos e União Soviética com o Terceiro Mundo. A força política e publicitária do não-alinhamento, assim como sua amplitude e crescente número de países participantes em cada reunião, terminou por pressionar os policy makers de ambas as superpotências a redefinir suas respectivas estratégias voltadas para a criação de zonas de influência. Ao longo desse processo, os programas de cooperação para o desenvolvimento tornaram-se um forte instrumento de barganha política para países que não fossem abertamente alinhados a um bloco ou outro. Da perspectiva dos governos terceiro-mundistas, uma política externa orientada pelo não-alinhamento permitia reivindicar neutralidade diante do conflito bipolar e, como resultado, ter aberto o diálogo e a possibilidade de negociar programas de "ajuda" sem a necessidade de respondê-los com fidelidade política à agenda internacional do país provedor.

Entretanto, um governo não-alinhado poderia ser mais ou menos importante para o jogo da Guerra Fria conforme pudesse oferecer vantagens ou representar empecilhos de ordem geopolítica. Tal relevância podia ser medida a partir das seguintes características: 1) a detenção de um posicionamento geográfico estratégico para a segurança de rotas comerciais marítimas ou terrestres, assim como a importância do acesso aos seus portos para a estratégia naval das superpotências; 2) um posicionamento geográfico interessante para a contenção da projeção de poder político ou territorial do bloco antagônico, 3) a posse de recursos energéticos e matérias-primas; 4) as características econômicas, o potencial militar e a representação político-ideológica assumida pelo governo; 5) o combate doméstico às organizações políticas simpáticas ou filiadas ao bloco antagônico.

A rivalidade competitiva entre as duas superpotências produziu, portanto, a valorização de certas zonas do Terceiro Mundo como espaços privilegiados do conflito da Guerra Fria (KENNEDY, 1989; HOBSBAWN, 1994). No caso do Egito, o não-alinhamento era uma dimensão estruturante de sua política externa, mas não era a única. Alçado ao papel de liderança pan-arabista, o governo de Gamal Nasser possuía uma agenda internacional própria e associada ao intervencionismo político e militar em seu entorno regional ${ }^{6}$. A conquista de uma estatura política

6 A política externa para o Oriente Médio do regime Nasser foi particularmente ativa. Além da participação direta em três guerras (Guerra de Suez, Guerra do Iêmen, Guerra dos Seis Dias), o Egito também patrocinou com dinheiro e armas grupos insurrecionais contra seus rivais árabes. Especialmente contando com a simpatia de grupos nativos pan-arabistas, o governo Nasser armou e financiou movimentos contrários aos governos do Rei 
internacional, expressa na condição de um dos líderes do anticolonialismo e da emancipação do "povo árabe", serviu, nesse caso, para redimensionar a importância geopolítica do Egito diante da Guerra Fria. Nesse ponto, destaca-se a relação entre duas dimensões complementares da política externa. A primeira delas definia-se pelas vantagens existentes diante da condição de país periférico subordinado ao jogo da Guerra Fria, isto é, a política externa egípcia posicionava-se no conflito da Guerra Fria buscando lograr maneiras de explorar a tensão existente entre Estados Unidos e União Soviética para celebrar vantajosos acordos de cooperação internacional para o desenvolvimento com ambas as superpotências. A segunda dimensão dizia respeito à política externa regional, fator esse de grande importância para reforçar a estatura internacional do Egito como liderança árabe e, como consequência, aumentar seu poder de barganha nas negociações internacionais. A maneira como o governo Nasser lograva projetar seu poder sobre os países de seu entorno geográfico impactava diretamente os interesses regionais das duas superpotências. O valor geoestratégico atrelado ao Egito no jogo da Guerra Fria estava, portanto, diretamente associado à sua capacidade de efetivamente exercer o papel de liderança regional e influenciar o jogo político de seu entorno imediato.

Entretanto, se a formalização dos acordos de cooperação internacional para os programas de desenvolvimento egípcio ocorriam porque o Egito exercia um papel potencialmente importante para a configuração dos voláteis cenários geopolíticos regionais, resta perguntar: seriam tais acordos efetivamente expressivos e duradouros? Para responder a tal questão, é necessária uma breve contextualização. As políticas de crescimento econômico dos anos de 1950 e de 1960 foram fortemente influenciadas pela preponderância das teorias desenvolvimentistas entre os economistas e os cientistas políticos. Tanto os programas de "ajuda" estadunidense como soviético eram apresentados, do ponto de vista teórico, como uma forma de valorização do processo de industrialização da periferia, sendo a indústria a representação do "progresso" ou da "modernização". O desenvolvimentismo egípcio, expresso através de seus principais programas voltados para a transformação da base produtiva, até então predominantemente agrícola, não escapava desse paradigma maior de seu tempo: buscava-se viabilizar um processo de industrialização acelerada capaz de incrementar a renda nacional, melhorar o nível médio de vida e fortalecer a segurança do Estado diante das ameaças externas.

Hussein (Jordânia), Rei Faisal (Arábia Saudita), General Kassam (Iraque), entre outros. Sobre a "guerra fria árabe”, ver Kerr (1965). 
No plano geopolítico, a importância internacional do Egito durante as décadas de 1950 e de 1960 era devida aos seguintes fatores: 1) natural-geográficos, já que tratava-se do país no qual localizava-se o delta do rio Nilo e o Canal de Suez, além de o país compor uma região que divide África e Ásia, o mar Mediterrâneo e o Vermelho; 2) políticos, por ser o Estado com maior influência política na região, e até então o único dotado de instituições modernas; 3) econômicos, posto que o Egito era a primeira economia do mundo árabe; 4) culturais, pois contava com as principais industrias musicais e cinematográficas de todo o Oriente Médio, assim como os maiores meios de comunicação e instituições de ensino prestigiosas, como a Universidade Al-Azhar; e 5) demográficos, posto ser o país mais populoso de toda a África do norte e Oriente Médio, com cerca de 30 milhões de pessoas durante as décadas de 1960 e de 1970 (HINNERBUSCH, 2003; LAURENS, 2007). Diante de uma região com estruturas políticas frágeis ou ainda em formação, a política externa regional do governo Nasser foi usada para potencializar a estatura internacional do país. A compra de armas soviéticas pelo Egito em 1955 resultou numa primeira aproximação entre esse país e a União Soviética. Desde então, a cooperação rapidamente foi estendida para setores não militares. Fora do Pacto de Varsóvia, o Egito foi o primeiro país do Terceiro Mundo a efetivamente receber esse tipo de atenção da política externa de Moscou (LAURENS, 2007; WATERBURY, 1983). Esse, por sua vez, rapidamente multiplicaria suas relações com a periferia global, ofertando apoio financeiro, técnico, político e militar aos governos nacionalistas que, em contrapartida, servissem de algum modo aos interesses geoestratégicos da União Soviética no contexto da Guerra Fria.

Na ocasião, tal fenômeno significou o fim do monopólio do bloco Ocidental como agente único da promoção do desenvolvimento no Terceiro Mundo, tornando os programas de cooperação internacional de diferentes naturezas, oferecidos pela União Soviética, um instrumento efetivo de incremento das relações entre essa e os novos Estados africanos e asiáticos emancipados do jugo colonial. A competição entre as duas superpotências da Guerra Fria por novas e maiores zonas de influência permitiu com que um grupo de países não-alinhados a qualquer um dos dois blocos buscasse suavizar sua dependência externa para a viabilização dos programas de desenvolvimento domésticos, multiplicando seus provedores de "ajuda externa". Dentre os países não-alinhados, o caso do Egito porta a singularidade de ter inaugurado essa via de desenvolvimento "multidependente", a partir da compra de armas soviéticas em 1955. 
Até então, os principais parceiros para o fornecimento de material bélico e de cooperação econômica para o Egito eram a Grã-Bretanha e a França. Os principais mercados importadores da produção nacional egípcia eram igualmente esses dois países, mais os Estados Unidos. Esse último, durante os primeiros anos de governo Nasser, exerceu o papel de provedor de créditos e apoio técnico para programas chave do planejamento estatal (WATERBURY, 1983). Em função do forte caráter anticolonialista do movimento dos Oficiais Livres, que levou Nasser ao poder, as tensões com a França e, principalmente, a Grã-Bretanha tornaram-se latentes (POMMIER, 2008). O contrário ocorria com os Estados Unidos, já que esse não portava consigo o peso de um passado colonialista. Além disso, esse país era dotado de um atrativo adicional: os programas de ajuda anunciados no Point Four de Harry Truman, aspecto esse simbolicamente representativo para a incorporação sistemática dos programas de "cooperação para o desenvolvimento" nas relações dos Estados Unidos com países do Terceiro Mundo no contexto da Guerra Fria (RIST, 2013).

No caso do Egito, sua importância geoestratégica não foi dada de imediato pela sua posição no conflito global, mas forçada pelo seu próprio governo ao "convidar" a União Soviética para cooperar com seus programas de desenvolvimento econômico e incremento do poderio militar. O desenrolar das relações egípcias com ambas as superpotências seguiu, a partir daí, um equilíbrio tênue montado sobre um jogo de compensações estreitamente dependente do modo como se dava a inserção egípcia na dinâmica das relações interestatais do Oriente Médio. Sob a agenda do não-alinhamento, o Egito logrou fazer com que Estados Unidos e União Soviética estivessem envolvidos na viabilização da agenda nacionaldesenvolvimentista implementada na esfera doméstica. A seguir, propõe-se uma análise sobre a ajuda técnica e econômica americana durante o período de maior ativismo externo do governo Nasser.

\section{A cooperação estadunidense e o desenvolvimento egípcio}

Durante a crise de Suez (1956), uma série de consultores e técnicos americanos que trabalhavam em projetos de desenvolvimento no Egito (especialmente associados à renovação das técnicas de cultivo agrícola, como as plantações de algodão) saíram do país (BURNS, 1985; FERRO, 2006). Após o conflito, e com a aproximação entre Egito e União Soviética para níveis de cooperação além da 
esfera militar, o governo dos Estados Unidos reagiu à perda de influência direta sobre o governo egípcio, inaugurando a Doutrina Eisenhower (1957) ${ }^{7}$ O objetivo implícito dessa era conter a expansão do nacionalismo árabe e, consequentemente, isolar o governo egípcio (YAQUB, 2004). Assim, todos os acordos de cooperação com o Egito foram temporariamente suspensos, ao mesmo tempo em que os Estados Unidos aderiam ao bloqueio econômico criado por França e Grã-Bretanha para retaliar a nacionalização do Canal de Suez e das companhias estrangeiras britânicas e francesas instaladas no Egito. Com a Doutrina Eisenhower, os Estados Unidos mantinham uma promessa de apoio militar aos governos árabes que se sentissem ameaçados pela retórica expansionista do governo Nasser. Entretanto, a relação entre Egito e Estados Unidos retomou a normalidade com o desenrolar dos acontecimentos tanto na esfera regional como na política doméstica da República Árabe Unida. Na esfera regional, Nasser rapidamente provou ser útil à política externa estadunidense ao integrar a Síria e representar, com isso, um impedimento ao crescimento da influência soviética ancorada na revolução iraquiana do general Qasim, em 1958. Outro fator relevante aos olhos dos Estados Unidos: no plano doméstico, o governo Nasser perseguia toda organização política de esquerda identificada ou não com o comunismo (GORDON, 1992 ; CREMENS, 1963; KERR, 1965). Cabe lembrar que a ascensão de Qasim no Iraque e sua aliança com a União Soviética haviam inviabilizado a arquitetura do Pacto de Bagdá organizado pelos britânicos.

Assim, em maio de 1958, os termos da nova relação de cooperação dos Estados Unidos com o desenvolvimento econômico egípcio passaram a estar encarnados na Public Law 480 (PL 480), conhecido por Food for peace. Essa relação foi amplificada com a eleição de John Kennedy para a presidência americana, em 1960, em sincronia tanto com o lançamento pelo governo egípcio de seu primeiro Plano Quinquenal como da aprovação e implementação das novas "leis socialistas”. O governo Kennedy (1961-1963) concedia especial atenção aos nãoalinhados. Com relação ao governo Nasser, a mudança de percepção da cúpula do governo americano era radical: o nacionalismo árabe, longe de ser um canal para a entrada do comunismo, passava a ser visto como uma forma de bloquear o expansionismo do mesmo (BURNS, 1985).

7 De acordo com a Doutrina Eisenhower, uma país do Oriente Médio poderia requerer ajuda externa estadunidense militar ou econômica caso se sentisse ameaçado por algum país aliado ao bloco soviético. No livro Containing Arab Nationalism, Salim Yaqub (2004) defende que a implementação da Doutrina Eisenhower tinha como principal objetivo controlar a política regional do governo Nasser. 
Assim, através da PL 480, navios norte-americanos carregados de trigo e alimentos passaram a descarregar em portos egípcios, contribuindo de maneira significativa para aliviar a dependência de alimentos importados e favorecendo a manutenção do balanço de pagamentos em ordem. Entre janeiro de 1961 e fevereiro de 1962, a administração americana assinou três acordos no âmbito do programa Food for Peace com o governo egípcio, nos quais se comprometia a prover 170 milhões de dólares em commodities (BURNS, 1985). Esses acordos iniciais foram suplementados por uma segunda rodada de acordos em que estava previsto o incremento da ajuda em 24 milhões de dólares em uma segunda rodada e 43 milhões em uma terceira. Em 1961, o provimento de trigo americano (no quadro da PL 480) ao mercado egípcio contabilizava $77 \%$ do total de importações egípcias dessa commodity. Em 1962, esse montante chegou a atingir $99 \%$ das importações nacionais do mesmo produto (BURNS, 1985). Fatores externos, como a morte de Kennedy, a ascensão de Lyndon Johnson à presidência americana e o engajamento egípcio cada vez mais profundo na guerra do Iêmen (1962-1967), coincidiram para arrefecer novamente as relações entre Egito e Estados Unidos em 1965. Em 1966, o programa de ajuda foi novamente retomado, mas dessa vez em menor escala.

O programa Food for peace representou o principal eixo da cooperação para o desenvolvimento entre o Egito e os Estados Unidos. Através da PL 480, a cooperação cobriu o período total entre 1954 e 1966, tendo sido particularmente relevante entre 1958 e 1964 . Durante o período total, cerca de 643 milhões de dólares foram enviados ao Egito por navio na forma de grãos e alimentos que serviam em grande medida para o consumo urbano (BURNS, 1985).

Com relação ao comércio propriamente dito entre os dois países, os Estados Unidos jamais deixaram de ser um parceiro comercial importante para o Egito. Em 1954, os estadunidenses representavam $11 \%$ das importações egípcias e $5 \%$ das exportações. Em 1962, em pleno processo de implementação do Plano Quinquenal egípcio, o governo Nasser importava 25\% da soma de todos os seus produtos dos EUA e exportava $6 \%$ a esse parceiro. Já em 1965, a relação era de $36 \%$ de importações e $3 \%$ das exportações aos EUA (BURNS, 1985).

Cabe ressaltar o impacto direto que a provisão de alimentos e grãos norteamericanos produzia no orçamento do Estado egípcio. Isso porque a dependência de alimentos importados para suprir uma população em pleno crescimento demográfico representava um fardo às contas do Estado que, além disso, ainda subsidiava equipamentos e matérias-primas necessárias à produção agrícola. 
A provisão de alimentos e grãos americanos, em um montante significativo como aquele em que foi negociado, permitia ao governo egípcio redirecionar parcela expressiva do orçamento estatal, normalmente destinado a comprar tais commodities, para efetivamente investi-los em programas de modernização da indústria, infraestrutura e produção agrícola. Isso é particularmente relevante quando lembramos que, entre 1960-1965, vigorava o ambicioso Plano Quinquenal cujo objetivo anunciado era industrializar massivamente o país em um curto espaço de tempo. Em outubro de 1962, após uma avaliação positiva do governo Kennedy sobre as relações desenvolvidas entre os Estados Unidos e o Egito a partir da PL 4808, decide-se pelo incremento da cooperação internacional com o anúncio do aporte de 431.8 milhões de dólares em alimentos e grãos para o triênio 1963, 1964 e 1965 (BURNS, 1985).

Durante esses últimos três anos, entretanto, o agravamento da guerra do Iêmen desgastou as relações entre Nasser e Kennedy. A despeito do reconhecimento da legitimidade da república iemenita feita pelo presidente Kennedy em 1962, o prolongamento da guerra civil interna e, principalmente, o crescimento das tensões entre o Egito e a Arábia Saudita fizeram com que os estrategistas estadunidenses revisassem sua posição original diante do conflito: percebia-se uma crescente ameaça de o conflito transbordar as fronteiras e impactar sobre a segurança dos poços de petróleo sauditas. Essa posição foi confirmada pelo sucessor de Kennedy, Lyndon Johnson, que também temia o engajamento das Forças Armadas egípcias em território iemenita, posto que isso contribuía para reforçar os laços de dependência militar do Egito com a União Soviética (KHALIDI, 2009; KERR, 1965).

O governo Johnson, por sua vez, insatisfeito com o desenrolar da participação egípcia nos eventos da região e sem nutrir pessoal afeição à figura de Nasser, passou a articular internamente para derrubar os acordos que comprometiam os Estados Unidos a prover ajuda em alimentos e grãos ao Egito para o triênio 1963-1965. Burns narra as discussões internas dentro do congresso e o peso da participação do lobby judeu para interromper os acordos de cooperação (BURNS, 1985).

Como resultado, em 1965, a ajuda externa americana é interrompida. Em 1966, quando se estimava a necessidade de o governo egípcio importar cerca de 300 milhões de dólares em alimentos e grãos, o governo americano volta a propor a integração do Egito na PL 480 nos mesmos marcos do período anterior.

8 Embora as relações entre Kennedy e Nasser fossem predominantemente positivas, existiam algumas desavenças, como ficou patente no caso da Guerra no Congo, no qual cada país apoiava lados antagônicos do conflito. 
Entretanto, nessa ocasião, o montante oferecido foi bem inferior aos anteriores: 55 milhões de dólares ao longo de seis meses (BURNS, 1985).

Como observou Mabro (1975), o grande sucesso da política externa do governo Nasser em relação à Guerra Fria foi assegurar a ajuda americana em períodos chave de grande investimento, ao mesmo tempo em que ampliava com a União Soviética o comprometimento dessa com os programas para a industrialização egípcia. Isso explica, em parte, a alta taxa de crescimento econômico egípcio entre 1957 e 1964. Tal crescimento contínuo foi enormemente financiado por acordos de cooperação internacional proclamados com os dois blocos. Os Estados Unidos mantinham a cooperação, comprometendo-se a comprar parte da produção egípcia, principalmente entre 1959 e 1962 . Vejamos, a seguir, o papel desempenhado pelos acordos de cooperação soviética durante o mesmo período.

\section{O papel da cooperação soviética para a industrialização do Egito}

No caso da relação egipto-soviética, ocorreu uma maior diversificação entre os setores mobilizados. Na esfera militar, por exemplo, a cooperação soviética teve início após a venda de armas militares repassadas ao Egito através da Checoslováquia em 1955 e estava inscrita na nova estratégia do governo de Nikita Khrushchev, orientada para disputar zonas de influência com o bloco ocidental no Terceiro Mundo.

O Egito tornou-se um elemento importante para a nova estratégia internacional soviética e, do lado russo, o eventual sucesso da relação entre os governos Nasser e Khrushchev passou a ser percebido como um ativo portador de diferentes vantagens: 1) tratava-se de uma forma de adentrar zonas de influência tradicionalmente ocidentais (como o Oriente Médio); 2) reduzia a capacidade de ingerência dos Estado Unidos sobre uma região próxima à fronteira sudoeste do território russo, rompendo localmente com a estratégia estadunidense de contenção do expansionismo russo; 3 ) facilitava a saída da frota soviética pelos mares quentes do Mediterrâneo através do potencial acesso aos portos de Estados mediterrâneos “amigos”, como era o caso do Egito; 4) o possível sucesso da ajuda soviética na transformação do Egito em uma potência militar e industrial tornaria esse país uma imensa plataforma de divulgação do modelo de desenvolvimento russo. Tal fenômeno melhoraria a imagem da União Soviética diante do Terceiro Mundo e poderia proporcionar alianças com outros governos nacionalistas não-alinhados. 
A percepção dos estrategistas soviéticos dessas potencialidades significou, na prática, uma atenção especial, assim como certa tolerância com eventuais divergências entre Moscou e o Cairo.

A transformação das Forças Armadas egípcias em uma potência militar regional era um objetivo declarado dos Oficiais Livres desde sua ascensão ao poder. Assim, o mercado de armas soviético serviu, a partir de 1955, aos propósitos imediatos voltados para o incremento do potencial militar do país. De fato, o Egito tornou-se o principal comprador de material militar russo fora do bloco soviético, o que exprime algo sobre a importância dada ao Egito pela política soviética para o Terceiro Mundo (ver Tabelas 1 e 2). Segundo Henry Laurens (2007), somente a Índia possuía números comparáveis aos do Egito em termos de ajuda militar soviética.

Tabela 1. A venda de armamentos da União Soviética para o Terceiro Mundo, Oriente Médio e Egito entre 1954 e 1966 (em milhões de dólares)

\begin{tabular}{lcc}
\hline & $1955-1959$ & $1960-1966$ \\
\hline Total de armas exportadas pela URSS para o Terceiro Mundo & 777 & 3.115 \\
Para o Oriente Médio & 546 & 987 \\
Para o Egito & 223 & 536 \\
Total do valor em armas importadas pelo Egito & 3.185 & 556 \\
\hline
\end{tabular}

Fonte: Dawisha, 1979.

Tabela 2. Valor gasto pelo Egito na compra de armamentos junto a todo o bloco socialista (ano/valor em milhões de dólares)

\begin{tabular}{cc}
\hline 1955 & 336 \\
$1956-57$ & 170 \\
1963 & 500 \\
1965 & 310 \\
\hline
\end{tabular}

No que diz respeito à ajuda econômica soviética (e do bloco socialista), essa teve início em 1958 após a assinatura de entre os dois países em 1957. Na ocasião, a União Soviética havia oferecido 700 milhões de rublos em empréstimos com baixos juros para financiar o primeiro plano trienal de industrialização egípcia (1957-1960). Os créditos seriam usados para importar equipamentos e contratar técnicos soviéticos (MABRO, 1975). 
Os termos dos acordos de cooperação econômica propostos pela União Soviética datam de 1958 e eram uniformes de maneira geral. Créditos eram cobertos em rublos a fim de serem pagos com $2.5 \%$ de juros em um período de dez a vinte anos. A União Soviética ainda se comprometia a comprar 50\% da produção de algodão a preços acima do mercado, como forma de pagamento (MABRO, 1975). O segundo acordo ocorreu em dezembro 1958 e estava relacionado ao financiamento da primeira etapa de construção da barragem de Assuã (cerca de 400 milhões de rublos). Em agosto de 1960, um novo empréstimo para o financiamento da segunda etapa de construção da barragem foi acordado, dessa vez no valor de 900 milhões de rublos. Os valores dos empréstimos nos anos seguintes foram enquadrados no primeiro e segundo Planos Quinquenais (1960-1965 e 1965-1970) e expressavam o progressivo engajamento soviético no financiamento dos programas de industrialização egípcios (ver Tabela 3).

\section{Tabela 3. Ajuda econômica soviética ao Egito (em milhões de dólares)}

\begin{tabular}{ccc}
\hline Ano & $\begin{array}{c}\text { Estimativa de montante cumulativo da ajuda } \\
\text { soviética desde } 1954 \text { até o ano em questão }\end{array}$ & Acréscimo anual \\
\hline 1961 & 681 & - \\
1962 & 711 & 30 \\
1963 & 765 & 54 \\
1964 & 1.282 & 517 \\
1965 & 1.408 & 126 \\
1966 & 1.415 & 7 \\
1967 & 1.535 & 120 \\
\hline
\end{tabular}

Fonte: Mabro, 1975.

Não havia oferta de cooperação do lado ocidental que se aproximasse dos termos vantajosos oferecidos pelos soviéticos. O Banco Mundial, por exemplo, era na maior parte do tempo reticente em realizar empréstimos ao setor público dos países “subdesenvolvidos” (WATERBURY, 1983; HANSEN, 1991). Nos termos dos acordos para créditos oferecidos pelos soviéticos, esses se comprometiam a avaliar o custo dos projetos, a expedição de equipamentos, os salários dos técnicos soviéticos e as despesas com suas viagens. O Egito era obrigado a cobrir todos os gastos dos técnicos soviéticos enquanto esses estivessem operando em solo egípcio, assim como estava comprometido em prover a eles materiais e adequadas condições de trabalho. A União Soviética também permitia a opção de estabelecer 
subcontratos para projetos de desenvolvimento econômico com outros países do Leste Europeu (DAWISHA, 1979).

Pela perspectiva soviética, era mais vantajoso apoiar os programas de desenvolvimento domésticos do Terceiro Mundo com financiamentos em projetos específicos do que adotar amplos programas de ajuda, existindo para tanto três razões centrais: 1) projetos específicos eram funcionais para fins de propaganda; 2) eram práticos para fins logísticos e organizacionais, dado ser mais fácil estimar os fundos necessários quando esses obedecem a projetos específicos, o mesmo valendo para o planejamento do número de técnicos a serem empregados; 3 ) o apoio a projetos específicos estimulava o desenvolvimento do setor estatal no país receptor, o que era em si um objetivo dos soviéticos (DAWISHA, 1979).

É importante ressaltar o papel dos programas de cooperação soviética na cobertura dos gastos empreendidos durante o esforço de industrialização egípcia. Entre 1955 e 1967, a União Soviética contribuiu com cerca de 826 milhões de dólares em ajuda não militar. Já os demais países do bloco soviético contribuíram com mais 709 milhões de dólares no mesmo período (MABRO, 1974, 1975; FERRIS, 2011). Mais da metade da ajuda soviética não militar foi direcionada às duas fases de construção da barragem de Assuã (ver Tabela 4).

Tabela 4. Créditos soviéticos ao Egito, 1955-1964

\begin{tabular}{lcccc}
\hline \multicolumn{1}{c}{ Data } & $\begin{array}{c}\text { Valor } \\
\text { (em milhões } \\
\text { de dólares) }\end{array}$ & Razão & $\begin{array}{c}\text { Taxa de } \\
\text { juros }\end{array}$ & $\begin{array}{c}\text { Prazo para } \\
\text { o pagamento }\end{array}$ \\
\hline Janeiro de 1958 & 175 & Plano trienal (1958-1960) & $2.5 \%$ & 12 anos \\
Dezembro de 1958 & 100 & Primeira fase de Assuã & $2.5 \%$ & 12 anos \\
Agosto de 1960 & 225 & Segunda fase de Assuã & $2.5 \%$ & 12 anos \\
Junho de 1963 & 44 & Plano quinquenal & $2.5 \%$ & 12 anos \\
Maio de 1964 & 282 & Plano quinquenal & $2.5 \%$ & 12 anos \\
\hline
\end{tabular}

Fonte: Ferris, 2011.

A barragem de Assuã foi o principal projeto isolado do qual participaram os soviéticos. Em 1958, isto é, dois anos após o abandono da participação estadunidense das negociações para a viabilização da construção da represa de Assuã, os soviéticos lograram fechar um acordo com as autoridades egípcias para participarem da execução do projeto. Durante o processo de implementação, mais de 300 fábricas soviéticas participaram da manufatura de cerca de 500.000 
toneladas de equipamentos utilizados durante a construção da represa (DAWISHA, 1979). Assim, os soviéticos proviam a expertise técnica e os equipamentos, mas não apenas isso: o projeto teria $27,8 \%$ do seu custo total pago pela União Soviética (ver Tabela 5).

Em 1964, durante o período em que Khrushchev realizou uma visita de dezesseis dias ao Egito para a inauguração da barragem de Assuã, a política soviética para o Egito era percebida por Moscou de maneira indubitavelmente satisfatória: a antes total influência ocidental sobre o Oriente Médio havia sido neutralizada e a política soviética havia progredido por etapas sucessivas. Isso contribuiu para que Khrushchev julgasse também de maneira positiva sua ampla política de apoio aos governos nacionalistas do Terceiro Mundo.

Tabela 5. Contribuição financeira soviética para a construção da barragem de Assuã (em milhões de dólares)

\begin{tabular}{lccc}
\hline & Custo total & Parcela soviética & Porcentagem soviética \\
\hline Primeira etapa & 614 & 100 & 16.2 \\
Segunda etapa & 515 & 225 & 40.8 \\
\hline Total & 1.165 & 325 & 27.8 \\
\hline
\end{tabular}

Fonte: Dawisha, 1979.

Em função do Egito pós-1957 e da união Soviética serem economias planificadas, tornou-se possível negociar o preço e o volume dos produtos a serem trocados sem maiores dificuldades. Existia entre os dois a prática de favorecer o Egito nos acordos comerciais, posto que o preço das mercadorias por esse exportadas eram fixadas a um valor acima do mercado (MABRO, 1975). Em particular, destacavase o preço do arroz e do algodão egípcios exportados para a União Soviética. Tais produtos serviam como forma de pagamento aos empréstimos acordados entre os dois países e eram não raramente fixados a um preço acima do mercado em $40 \%$ e $20 \%$, respectivamente (DAWISHA, 1979).

Para além da vantajosa relação comercial e financeira, os soviéticos estabeleceram também significativos acordos de cooperação na esfera educacional, com especial ênfase em formação técnica, visando a ocupação de funções administrativas específicas. Como observa Dawisha,

A construção de centros técnicos produziu impacto imediato no sistema educacional egípcio. Entre 1956 e 1975, a União Soviética contribuiu para a construção e equipamento de 43 centros de formação técnica, responsáveis 
pela graduação de 85.000 egípcios. A ênfase nos centros técnicos orientavase para a provisão de técnicas vocacionais básicas, mas também tinham relação com o crescimento do nível médio de alfabetização e com o ensino de habilidades gerenciais. (DAWISHA, 1979, p. 195. Tradução nossa) ${ }^{9}$.

Um fator externo contribuiu ainda para que a União Soviética ampliasse seu engajamento na promoção do desenvolvimento no Terceiro Mundo. No início da década de 1960, os soviéticos foram constrangidos a fazer avançar rapidamente seu programa de ajuda externa a governos não-alinhados, por acreditar existir uma concorrência "entre comunistas" advinda da China popular. Essa, após a ruptura das relações com a União Soviética ${ }^{10}$, passou a acusá-la abertamente de ser um Estado tão imperialista como seriam os Estados Unidos e de fazer uso de teses revisionistas para legitimar internamente uma política externa apoiada na “coexistência pacífica” com o bloco ocidental (KAMISKY; KRUK, 1988). No lado soviético, o efeito produzido pela competição "entre comunistas" foi a impulsão de uma política de demarcação de suas zonas de influência no Terceiro Mundo, ampliando o volume de ofertas para manutenção de relações privilegiadas com certos Estados chave para sua estratégia de projeção geopolítica.

O Egito, diante desse novo contexto no qual as opções de barganha se estendiam também dentro da própria fricção do bloco comunista ${ }^{11}$, fortaleceu sua condição de objeto prioritário da política assistencialista soviética. A despeito das tensões existentes por conta de posicionamentos divergentes no tabuleiro regional, Egito e União Soviética mantiveram relações estreitas e significativamente mais estáveis que as relações entre egípcios e norte-americanos durante o período aqui analisado. Com a derrota na Guerra dos Seis Dias (1967), o Egito perdeu parte importante de sua frota aérea e, mais grave, passou a ter parte de seu território - o Sinai - ocupado. Em outras palavras, a guerra reduziu consideravelmente a capacidade de o governo Nasser continuar a agir como um ator decisivo no

9 The construction of technical centers had the most immediate effect on the educational system in Egypt. Between 1956 and 1975, the Soviet Union helped to build and equip 43 such centers from which over 85.000 Egyptians have graduated. Emphasis in the centers has been on providing basic vocational skills but has also dealt with raising standards of literacy and with providing management skills.

10 Após anos de crescentes tensões diplomáticas, a ruptura das relações entre Egito e Estados Unidos ocorreu formalmente em 1963.

11 Embora Nasser tenha obtido certo volume em ajuda alimentar da China, especialmente após a suspensão da PL 480 pelos Estados Unidos em 1965, o fato é que, como bem aponta Dawisha (1979), o governo de Mao não possuía meios nem econômicos nem militares de fazer concorrência com a União Soviética por zonas de influência comunistas no Terceiro Mundo. 
Oriente Médio, seja na condição de liderança árabe, seja na função de agente dinamizador das tensões da Guerra Fria que envolviam a região (LAURENS, 1991; OREN, 2002). O resultado foi a impossibilidade de manutenção de uma política externa capaz de instrumentar o peso geopolítico do país para negociar apoios com os dois lados da Guerra Fria. Efetivamente, a partir de então e durante os anos seguintes, o Egito reduziria enormemente o caráter autônomo de sua política externa para se tornar mais vulnerável e dependente do suporte exclusivo do bloco soviético. Segundo o próprio Gamal Nasser, as circunstâncias haviam feito do não-alinhamento uma impossibilidade factual (HEIKAL, 1972, 1986; FERRIS, 2013; DAWISHA, 1976).

\section{Considerações finais}

Ao compararmos a cooperação internacional entre Egito, Estados Unidos e União Soviética, foi preciso considerar representado pelo governo Nasser para cada uma das superpotências em termos regionais e globais, dado o contexto da Guerra Fria. Assim, a maior propensão do lado soviético em arcar com os custos de programas de ajuda externa vantajosos ao Egito ocorria justamente em função desse país possuir elevada importância na estratégia soviética de projeção de seu poder estatal no globo. Tal percepção da importância egípcia não ocorria, ao menos na mesma escala, do lado das prioridades definidas pelos Estados Unidos. No caso, após um período de inicial desinteresse em atender as demandas do governo dos Oficiais Livres, os EUA acabaram pressionados a redefinir e valorizar uma janela de negociação aberta com o Egito. Tal revisão somente foi possível após o Egito “convidar” a União Soviética para contribuir com seus programas de obtenção de armamentos e desenvolvimento econômico. Do ponto de vista norte-americano, embora o Egito mantivesse um papel central na elaboração da estratégia estadunidense para o Oriente Médio durante o período 1955-1967, seu peso era contrabalançado pela existência de outros aliados regionais, como a Arábia Saudita e, num momento posterior, Israel. No caso soviético, o apoio regional existente para além do governo Nasser, como o ocorrido temporariamente na Síria e no Iraque, era mais fluido e instável.

Na política soviética, a condescendência com o elevado grau de autonomia dos movimentos nacionalistas não-alinhados, tal como expresso na relação especial desenvolvida com o Egito, representava algo mais profundo, como uma revisão 
das próprias teorias que até então orientavam a política externa daquele país. Buscando usar o exemplo de sua relação com o Egito para projetar sua influência sobre novos governos, os instrumentos de propaganda soviética reforçaram a percepção de ser o Egito de Gamal Nasser um modelo de sucesso para os países do Terceiro Mundo, garantido graças aos financiamentos e à expertise técnica soviética. A Guerra dos Seis Dias em 1967 e a subsequente reordenação da correlação de forças entre os Estados árabes esvaziaram a capacidade egípcia de agir regionalmente para manter-se em equilíbrio em relação ao jogo de forças dos interesses regionais de Estados Unidos e União Soviética. O resultado dessa transformação no tabuleiro geopolítico da região foi o fim das condições materiais que permitiram ao Egito utilizar o não-alinhamento como instrumento eficaz para viabilizar financiamentos, peças e técnicos para seus principais programa internos de desenvolvimento.

\section{Referências}

BURNS, William. Economic Aid and American Policy toward Egypt, 1955-1981. New York: State University of New York Press, 1985.

CARRÉ, Olivier. Le nationalisme arabe. Paris: Payot, 1993.

CREMEANS, Charles. The Arabs and the World: Nasser's Arab Nationalist Policy. New York: Praeger, 1963.

DAWISHA, Adeed. Egypt in the Arab World: The Elements of Foreign Policy. Toronto: Macmillan, 1976.

DAWISHA, Karen. Soviet foreign Policy towards Egypt. New York: Palgrave Macmillian, 1979. FARAH, Nadia. Egypt's Political Economy. Cairo: American University of Cairo: 2009. FERRIS, Jesse. Nasser's Gamble: How Intervention in Yemen Caused the Six-Day War and the Decline of Egyptian Power. Princeton: Princeton University Press, 2013. . Guns for Cotton? Aid, trade and the Soviet Quest for Base Rights in Egypt, 1964-1966. Journal of Cold War Studies, Vol.13, N.2, p. 4-38, 2011.

FERRO, Marc. Suez. Paris: Editions Complexe, 2006.

GADDIS, John. A Guerra Fria. Lisboa: Edições 70, 2005.

GORDON, Joel. Nasser's Blessed Movement: Egypt's Free Officers and the July Revolution.

Oxford: Oxford University Press, 1992.

HALLIDAY, Fred. Il Médio Oriente: potenza, política e ideologia. Milão: V\&P, 2005.

HANSEN, Bent. The Political Economy of Poverty, Equity and Growth: Egypt and Turkey.

Oxford: Oxford University Press, 1991. 
HARIK, Illya. Economic Policy Reform in Egypt. Cairo: American University Press, 1997. HEIKAL, Mohamed. Cutting the Lion's Tail: Suez Through Egyptian Eyes. Londres: Arbor House Pub, 1986. . Nasser, les documents du Caire. Paris: Flammarion, 1972.

HINNERBUSCH, Raymond. The International Politics of the Middle East. Manchester: Manchester University Press, 2003.

HOBSBAWN, Eric. Era dos extremos. São Paulo: Companhia das Letras, 1994.

JANSEN, Godfrey. Non-Alignment and the Afro-Asian States. New York: Praeger, 1966.

KAMISNKY, Catherine \& KRUK, Simon. La stratégie soviétique au Moyen-Orient. Paris:

Presses Universitaires de France, 1988.

KENNEDY, Paul. Ascensão e queda das grandes potencias. Rio de Janeiro: Campus, 1989.

KERR, Malcolm. The Arab World and the Cold War, 1958-1964. 1965. London: Oxford University Press, 1965.

KERR, Malcolm e YASSIN, El Sayed (Ed.) Rich and Poor States in Middle East: Egypt and the New Arab Order. Bolder: Westview Press, 1982.

KHALIDI, Rashid. Sowing Crisis. Boston: Beacon Press, 2009.

LAURENS, Henry. Le grand Jeu: Orient arabe et rivalité internationales depuis 1945. Paris: Armand Colin, 1991.

. Orientales. Paris: CNRS Édition, 2007.

MABRO, Robert. The Egyptian Economy, 1952-1972. Londres: Oxford, 1974.

. Egypt's Economic Relations with the Socialist Countries. World Development, Vol. 3, n. 5, p. 299-313, 1975.

NASSER, Gamal. A revolução no mundo árabe. São Paulo: Edarli, 1963.

OREN, Michael. Six Days of War: June 1967 and the Making of Modern Middle East. Londres: Oxford University Press, 2002.

OWEN, Roger e PAMUK, Sevket. A History of the Middle East Economies in the Twentieth Century. Londres: Tauris, 1998.

POMMIER, Sophie. Égypte, l'envers du décor. Paris: La Découverte, 2008.

RIST, Gilbert. Le développement, histoire d'une croyance occidentale. Paris: Sciences Pó Press, 2013.

YAQUB, Salim. Containing Arab Nationalism: The Eisenhower Doctrine and the Middle East. Chapel Hill: The University Press of North Caroline, 2004.

WATERBURY, John. The Egypt of Nasser and Sadat. New York: Princeton, 1983. 